\title{
Teacher's Use of a Drawing Workshop as a Method of Art Therapy
}

\author{
Rsaldy B. Orazalieva $a^{1, \#, *}$, Olena O. Bila ${ }^{2, \#}$, Olena L. Pozdnyakova ${ }^{3, \#}$ and \\ Nataliya V. Derevyanko,"\#
}

${ }^{1}$ Kazakhstan Innovative University, Semey, Republic of Kazakhstan

${ }^{2}$ Izmail State University of Humanities, Izmail, Ukraine

${ }^{3}$ Khortytsia National Educational and Rehabilitation Academy, Zaporizhzhia, Ukraine

\begin{abstract}
Objective: The purpose of the study is to evaluate the effectiveness of a workshop in watercolour drawing by a future teacher of art as part of art therapy to improve mental state.

Background: In modern conditions of development of the innovation and educational process in higher education in the specialties "Fine Arts" and "Design" special attention is paid to the acquisition of professional skills and abilities of students to work in the art space of the Planer. In this regard, master classes are widely used in classes in higher education institutions, but most training is aimed at acquiring professional writing with watercolour.

Method: Workshop, as a quick and illustrative example in the performance of a watercolour etude by a teacher, is the strongest means of aesthetic impact, which is to show the secrets of drawing mastery, aesthetic techniques of working with watercolour, brush movements, the appearance of colour fillings, emphasizing a pictorial composition.

Results: In the course of the study, it was determined that using a drawing workshop as art therapy is an effective way to improve the mental state. Art-therapeutic work evokes positive emotions, helps form a more active life position, emotionally valuable acceptance of partners, and cohesion.

Conclusion: Fine art products constitute objective evidence of a person's mood and thoughts, which allows them to be used to assessing the mental state.
\end{abstract}

Keywords: Watercolour drawing, artistic image, art therapy, drawing practice, la prima method.

\section{INTRODUCTION}

Using methods of conducting a workshop as a system of creative display, aesthetic techniques of working in watercolour drawing effectively affect the development of artistic and creative abilities, and creative thinking of students of creative specialties. We consider the use of workshops in watercolour drawing as one of the therapy methods in specialised psychiatric institutions to improve the mental state of patients. Art therapy is a method of treating mental disorders and psychological issues through artistic creation. It is an interdisciplinary field of knowledge that exists at the intersection of psychology, pedagogy, medicine, and various arts. Art-therapeutic methods are used both for therapy and correction, as well as for prevention, socialisation, help in self-knowledge, and harmonious development of personality [1-3].

Due to the abundance of opportunities, art therapy has been widely used in psychiatric practice. Without replacing treatment with psychotropic drugs prescribed according to clinical indications, art therapy carried out by a trained specialist can significantly enrich the

${ }^{*}$ Address correspondence to this author at the Kazakhstan Innovative University, Semey, Republic of Kazakhstan; Tel: +77222562253;

E-mail: r.orazalieva@nuos.pro

\#These authors are equally contributed. arsenal of modern tools used in psychiatry, enhance the effect, and long-term results of comprehensive rehabilitation, and make its implementation as sparing and humane as possible. The latter is determined by the fact that the use of visual and plastic expressions of actual experiences and conflicts alleviates the patient's mental pain, which is inevitable upon directly discussing their issues with a therapist. As a result of this, art therapy is most prescribed for harmonisation and research of those aspects of mental life, which are not conscious or not quite conscious of deep conflict complexes for which words are ineffective: hardly or unsuitable at all [4]. In this meaning, we can refer to a wide niche that art therapy should occupy, along with other technologies for the social rehabilitation of mentally ill patients in comprehensive rehabilitation programs.

The introduction of art therapy in the activities of specialised psychiatric clinics and departments in recent years has been on the wave of a paradigm shift: "The biomedical paradigm of constructing and implementing psychiatric treatment is giving way to the biopsychosocial paradigm associated with the addition of psychopharmacotherapy to various forms of psychological and psychosocial care for patients, which is manifested in particular in strengthening the component of psychosocial rehabilitation and 
psychotherapy. A set of problems arises here. In domestic psychiatry, there is still no consensus on the place and role of psychosocial rehabilitation and psychotherapy in the system of psychiatric care. There are no agreed organisational forms of rehabilitation activity" [5;6].

The introduction of art therapy methods is hampered by their perception of a purely auxiliary and even optional treatment and rehabilitation element. Due to the novelty of art therapy for most domestic psychiatric institutions, we can also refer to the absence of any developed methodology and organisation of art therapy activities. The use of art therapy is often chaotic, thanks to the initiative of individual specialists. Art therapy constitutes a relatively new type of treatment and rehabilitation work with patients in specialised departments. Although the first attempts to introduce art therapy in these departments took place about a decade ago, art therapy has been applied more regularly over the past four and a half years $[7,8]$.

Scientific novelty. The study for the first time, based on representative material - the contingent of patients in the rehabilitation department of a large regional psychiatric hospital - investigated the dynamics of their mental state and quality of life in applying art therapy. Differentiated indications for the use of art therapy in the rehabilitation of patients with various mental disorders are determined. This method's modifications have been developed with consideration of the clinical characteristics of patients and the specific tasks of therapeutic and rehabilitation effects. The principles, stages, methodological approaches, and techniques of art-therapeutic work carried out in a typical psychiatric institution are described in detail; the role of art therapy at various stages of the rehabilitation process is clarified, as well as its place in the complex of rehabilitation measures [9].

One of the significant areas for the introduction of art therapy methods is specialised psychiatric institutions (departments) of compulsory treatment of patients who have committed socially dangerous acts (SDA), as well as psychiatric departments at correctional institutions, designed to stop the symptoms of mental disorders in prisoners. In such conditions, both foreign and domestic publications, problems, and features of art therapy are considered. A special group of art-therapeutic publications comprises works devoted to primary and secondary prevention of offenses based on the diagnosis and application of early intervention programs in adolescents and adults with asocial, aggressive tendencies $[10,11]$.

The purpose of the study is to evaluate the effectiveness of a workshop in watercolour drawing by a future teacher of art as part of art therapy for the comprehensive rehabilitation of the mentally ill.

\section{MATERIALS AND METHODS}

Watercolour is an excellent artistic work material that is convenient to use at workshops, work in the open air, also contributes to the cultivation of artistic taste, the culture of colour perception, watercolour helps in learning the form and space, with its aesthetic possibilities develops the figurative thinking of future teachers of art. The workshop is a creative demonstration of the teacher's stages and the parallel performance of the same task by students. The author's conducting of the workshop coincides with the practice and positions that existed in the work of the masters of the Renaissance when the student watched and improved by observing the working master. The workshop is a visual demonstration of the methods and techniques of working in watercolour and is an instant, expressive illustration confirming the teacher's words. Also, a workshop, as a quick and illustrative example in the performance of a watercolour etude by a teacher, is the strongest means of aesthetic impact, which is to show the secrets of drawing mastery, aesthetic techniques of working with watercolour, brush movements, the appearance of colour fillings, emphasizing pictorial composition. The workshop also helps create a working mood, an atmosphere of creativity, and inspiration for all participants in the event, influencing students and explaining the material under study.

The study was carried out at the Zaporizka Oblast Psychiatric Hospital (Zaporizhzhia, Ukraine). The study group consisted of 66 males and females aged 19-48 years. The average age was 30.8 years, of which 36 were women, and 30 were men. The control group comprised 50 males and females aged 22-45 years. The average age was 32.6 years, of which 26 were men and 24 were women. We studied the formal features of the drawings of patients of four nosological groups - with depression, schizophrenia, organic mental disorders, and mania (Table 1). The choice of these mental diseases is conditioned by the fact that each of them is described by a specific set of clinical manifestations reflected in the drawings, affecting their various formal features. 
Table 1: Diagnostic Distribution of Patients of the Main and Control Groups

\begin{tabular}{|c|c|c|c|c|}
\hline \multirow{2}{*}{ Diagnoses (according to ICD-10) } & \multicolumn{2}{|c|}{ Study group } & \multicolumn{2}{|c|}{ Control group } \\
\hline & Abs. & $\%$ & Abs. & $\%$ \\
\hline F32. Depressive episode & 20 & 30.3 & 15 & 30 \\
\hline F30. Manic episode & 6 & 9.1 & 4 & 8 \\
\hline F20. Schizophrenia & 12 & 18.2 & 10 & 20 \\
\hline $\begin{array}{l}\text { F00-F09. Organic brain disease (delirium, dementia, amnesia, and other } \\
\text { cognitive disorders) }\end{array}$ & 18 & 27.3 & 13 & 26 \\
\hline Total & 66 & 100 & 50 & 100 \\
\hline
\end{tabular}

Of the known varieties of art-therapeutic approaches, preference was given to the thematic approach. It is described by relatively high structuring and no less high directivity, which in our opinion, meets the expectations of most patients, the possibility of conducting courses of short and medium duration, accessibility for patients, including those who have no experience in artistic creation, with the use of a wide range of therapeutic and correction factors exposure. Sessions were held 3 to 5 times a week, lasting 2-3 hours, for 6 weeks. Classes had the usual structure for thematic group art therapy: a) introduction and "warmup"; b) the choice of topic and visual work; c) discussion of drawings and completion of the session. The number of group members ranged from 7 to 10 people. The groups were semi-open and homogeneous by nosological and age characteristics.

Starting work, the following tasks were set:

- $\quad$ the weakening of symptoms present in patients, associated with both the disease itself and the reaction to it, optimizes their mental state and social functioning;

- achieving a higher level of psychosocial adaptation, in particular, a better understanding of the specifics of their condition, causes, and mechanisms of the disease; the formation of self-regulation skills; development of the ability to express feelings and thoughts in verbal and nonverbal forms;

- $\quad$ strengthening the sense of "l", improving the ability to make independent decisions, acting in conflict and stressful situations, and forming a stable system of socially significant ties, interests, hobbies, etc.

The art-therapeutic process involved several stages:
1. The preparatory stage was to explain to patients the features of the approach, as well as the rules of behaviour in the group; the group members were introduced to the art-therapeutic space, explaining the conditions for drawing tests.

2. At the stage of formation of the system of psychotherapeutic relations and the beginning of the visual activity, techniques were applied that contributed to the development of creative imagination, activation of patients, and increase of their ability to self-control.

3. At the stage of strengthening and developing psychotherapeutic relations, exercises were used that allowed patients to express their thoughts and feelings in an artistic and dramatic form, including those associated with significant problem situations. Interactive techniques and a multimodal approach have contributed to the development of communication skills, strengthening a sense of identity and mainstreaming psychological defence mechanisms. These techniques also contributed to clarifying and understanding the system of their relationships by patients, including their attitude towards themselves.

4. At the final stage, techniques were applied to a greater extent, allowing to accumulate the acquired experience of the group and individual work and, at the same time, to implement a "softer" way out of the psychotherapeutic process.

A comparative assessment of the severity of the mental state of patients was carried out according to the art-therapeutic scales of formal elements (ATSFE). The method was developed by American art therapists L. Gantt, and K. Tabon based on the determination of the complex of formal features of the picture and has 
mainly clinical application. At the same time, it can be used to solve other problems of psychodiagnostics the assessment of mental processes, conditions, and personality traits. The method was developed based on many years of clinical research and determination of a set of formal signs of a picture that would help to quantify various visual features that correlate with manifestations of mental disorders. Gantt and Tabon emphasise that ATSFE is based on the work of several well-known art therapists who have attempted to build a psychodiagnostic model based on an analysis of the formal features of the pattern. Upon evaluating the drawings, 14 scales were used. Each of them quantitatively measures a specific formal attribute. All of them together allows us to identify different "profiles" of formal signs characterising various mental disorders or conditions, as well as (presumably) personality traits manifested in the style of the drawing [12].

As a figurative task that satisfies all these requirements and makes it possible to obtain the most informative diagnostic products, the creation of a drawing of a person picking an apple from a tree (PPPAT) was chosen. Offering this technique to the subjects, the following rather simple instruction was used: "Draw a person picking an apple from a tree".

The main hypothesis underlies the diagnostic application of PPPAT is that a combination of various formal features of the pattern (excluding its substantial features) correlates with various diagnostic categories associated with basic psychiatric diagnoses. Based on the formal features of the figure, one can put forward the correct hypotheses regarding the basic psychiatric diagnoses, and the probability of the correct answers significantly exceeds the threshold of randomness.

\section{RESULTS}

A comparative assessment of the severity of the mental state of patients on the ATSFE scale before art therapy and prospective follow-up revealed its positive dynamics (Table 2).

Before art therapy, $68 \%$ of patients had mild mental disorders, after $-14 \%(p<0.001)$, in prospective followup - 20\% ( $p<0.001)$. Moderately severe disorders before art therapy were observed in $32 \%$ of patients,

\section{Table 2: Content Description of Art-Therapeutic Scales of Formal Elements}

\begin{tabular}{|c|c|c|}
\hline No. & Scale & Meaning \\
\hline 1 & Scale 1 , colour value & $\begin{array}{l}\text { How much colour is used to create the picture? Was colour used only to create contours of } \\
\text { objects or also for colouring inside objects? }\end{array}$ \\
\hline 2 & Scale 2, Colour Adequacy & $\begin{array}{l}\text { Does the colour match the subject (for example, colours like pink, red, yellow, etc. are more } \\
\text { suitable for the image of the human body)? }\end{array}$ \\
\hline 3 & Scale 3, Energy & How much effort did the author spend on creating the drawing? \\
\hline 4 & Scale 4, Space & How much space does the drawing occupy relative to the total space of the sheet? \\
\hline 5 & Scale 5, Integration & How complete is the composition? How consistent are the elements with each other? \\
\hline 6 & Scale 6, Logic & $\begin{array}{l}\text { Do the objects correspond to the theme of the picture ("A person picking an apple from a } \\
\text { tree")? }\end{array}$ \\
\hline 7 & Scale 7, Realism & $\begin{array}{c}\text { Are objects recognisable in the image? (The more realistic and three-dimensional objects } \\
\text { are, the higher the score) }\end{array}$ \\
\hline 8 & Scale 8, Problem Solving & How effective is the way to get an apple? \\
\hline 9 & Scale 9, Level of Development & $\begin{array}{l}\text { This show reflects the degree of maturity of the pictorial "language" and corresponds to the } \\
\text { psychological age of the test subject (child or adult). For those adults who have not } \\
\text { developed their visual skills, the drawings will correspond to at least the teenage phase }\end{array}$ \\
\hline 10 & $\begin{array}{l}\text { Scale 10, Details of facilities and } \\
\text { the environment }\end{array}$ & How detailed is the image? \\
\hline 11 & Scale 11, Line Quality & How much control over the process of creating lines? \\
\hline 12 & Scale 12, Man & $\begin{array}{c}\text { Does the depicted figure resemble a human? The size of the figure should be taken into } \\
\text { consideration. With a small size of the figure, some significant details will be missing that are } \\
\text { better transmitted if the figure is large enough. At the same time, the figure can be quite } \\
\text { proportional and depicted in volume }\end{array}$ \\
\hline 13 & Scale 13, Rotation & Is there a deviation of the figures (person, tree) from the vertical axis? \\
\hline 14 & Scale 14 , Perseveration & Is there multiple and uncontrolled repetition of individual elements? \\
\hline
\end{tabular}


after - in $10 \%(p<0.001)$. In general, at the end of the course of art therapy, about $70 \%$ of patients could be considered healthy; the same number of patients without mental disorders remained in medical history. In the control group, before and after treatment, the severity of violations was comparable with the study group. However, the group of patients with moderately severe disorders remained in prospective follow-up, which statistically significantly distinguished it from the study group $(p<0.05)$.

The dynamics of the mental state of patients in the study group was described by a decrease during treatment of the number of patients with slight improvement (during $-45 \%$, after $-21 \%$, at $p<0.02$ ) and an increase in the number of patients with a substantial (from $27 \%$ to $34 \%$ ) and significant (from $0 \%$ to $45 \%$ at $p<0.001$ ) improvement in mental state. At the same time, the proportion of patients whose mental state remained unchanged decreased from $18 \%$ to 0 ( $p$ $<0.01)$. Follow-up data indicate a decrease in the number of patients characterised by a substantial (up to $18 \%$ ) and insignificant (also up to $18 \%$ ) improvement in their mental state, and an increase to $57 \%$ due to this number of patients with a significant improvement. In the control group, the number of patients with significant, substantial, and insignificant improvement after treatment is comparable to the study group and does not significantly differ statistically. However, the number of patients in whom the improvement of the mental state achieved as a result of treatment remained in the medical history was significantly higher in the study group than in the control group $(p<0.02$ and $p<0.01)$.

Furthermore, a qualitative clinical analysis based on the identification of leading psychopathological syndromes showed that the improvement in the condition of patients of the main group, compared with the control group, is significantly more pronounced and, above all, in people suffering from anxiety-phobic and somatoform disorders, as well as disorders adaptation. If improvement in the condition of patients is judged by the degree of reduction of psychopathological disorders, in general, despite some structural features, in the main and control groups, it is expressed approximately the same but is more stable upon using art therapy.

If we analyse the dynamics of indicators of social functioning and quality of life before and after treatment, then their improvement achieved in the study group is statistically more significant and more stable than in the control group. The most significant differences were observed in the degree of satisfaction with a number of areas: "physical performance" ( $p$ $<0.01$ ), "mental state", "physical condition", "intellectual productivity" ( $p<0.01)$, and "daily activity" $(p<0.02)$, "relations with relatives" $(p<0.05)$, etc.

Observations of the progress of group arttherapeutic work allow us to ascertain the effect of various factors and mechanisms of psychotherapeutic changes, including factors such as artistic expression and psychotherapeutic relationships interpretation, and the mechanism of verbal "feedback". The inclusion of art therapy - a psychotherapeutic method based on fine art - into a set of measures aimed at the rehabilitation of mentally ill patients increases their effectiveness due to a significant improvement in the quality of life and social functioning, as well as a more stable reduction of psychopathological symptoms.

The results of a comparative clinical analysis of the degree and rate of reduction of mental disorders in patients in the main and control groups were equal, but the improvement achieved with the use of art therapy during the follow-up period (10-12 months) was more stable and lasting $(p<0.01)$. An analysis of the dynamics of assessments of the social functioning and quality of life of patients before and after art therapy showed that their increase in the main groups was statistically more significant and stable than in the control group, especially in such areas as general wellbeing, health, working capacity, family relations, and social contacts $(p<0.001)$. General indications for the use of art therapy for rehabilitation purposes are states of personality maladaptation due to chronic and protracted mental disorders.

If we analyse the dynamics of indicators of social functioning and quality of life before and after treatment, then their improvement achieved in the study group is statistically more significant and stable than in the control group. Moreover, the most significant differences were observed in the areas: "satisfaction with physical performance", "satisfaction with mental state", "satisfaction with physical condition", and "satisfaction with intellectual productivity" ( $p$ $<0.01$ ), "satisfaction with daily activity" ( $p<0.02)$, "satisfaction with relationships with relatives" $(p<0.05)$.

Qualitative clinical and psychological analysis, based on the identification of leading psychopathological syndromes, gave reason to determine the indications for art therapy for mental 
disorders. These include, anxiety-phobic disorders: agoraphobia with and without panic attacks, social phobias, mixed anxiety, and depressive disorders, as well as anxiety-hysterical (hysterophobic) disorders; somatoform disorders: somatised, hypochondriacal, chronic pain disorders, autonomic dysfunctions; reactions to severe stress and adaptation disorders: PTSD, prolonged depressive reaction, mixed anxiety and depressive reaction, neurasthenia; obsessivecompulsive disorder.

Observations requiring further special research and verification suggest that the effectiveness of art therapy is somewhat higher with prolonged depressive reactions of adaptation disorders, agoraphobia, social phobias, and somatoform disorders.

\section{DISCUSSION}

According to L. Gantt and C. Tabone, the use of a quantitative assessment of different attributes (from 0 to 5 points) measured with ATSFE suggests the varying degrees of severity of a particular sign. However, higher grades are not necessarily more favourable than low grades. Thus, for example, high marks on scale No. 3, Energy, or on the scale No. 10, Details may be associated with a manic state. Only if sufficient studies are covering both healthy and mentally ill subjects can we conclude what indicators on different scales describe the norm [13-16]?

Pictures of patients with depression have fewer colours and details and occupy a smaller area than the control. The environment is not represented; there are basic elements - a person, a tree, and an apple. The solution to the problem is usually shown: a person reaches for an apple but does not always hold it in their hands. Often the image of a person's figure is simplified and schematised. However, if we compare the drawings of patients with depression at the beginning of treatment and shortly before discharge from the hospital, we can see how such schematised images of a person give way to more carefully drawn ones. Thus, the most significant decrease in major depression is noted on the following scales: Scale No. 1, Colour Meaning, Scale No. 2, Colour Adequacy, Scale No. 3, Energy, Scale No. 4, Space, Scale No. 7, Realism, Scale No. 10, Details, Scale No. 12, Human.

Given that depression is a very common mental disorder, and can be connected with other diseases the depressive phase of bipolar affective disorder, recurrent depressive disorder, dysthymia, depressive phase of cyclothymia (according to ICD-10) - as well as psychogenic disorders, or act as a compound part of more complex clinical pictures, it is necessary to clarify the specifics of depressive manifestations in the drawings of patients with these disorders. A more indepth study is required of how a combination of ATSFE indicators characterises different subgroups of depressed patients. Evaluation of the features of the pattern indicating depression, based on the use of ATSFE, can be difficult if combined with others with other mental disorders or syndromes with a more complex structure.

Like depression, organic mental disorders make up a large group. It combines conditions that are described by psychological and behavioural abnormalities due to temporary or persistent brain dysfunctions. Mental disorders included in this group have different clinical manifestations, which depends on the aetiology, the intensity of the pathological manifestations, the topography of the damage to the brain structures, premorbid personality traits.

Describing the drawings of patients with organic mental disorders, the products of patients with more pronounced signs of intellectual and mental decline were taken as a framework. It should be noted that the drawings of patients with an organic mental disorder are often described by the presence of only one or two colours, but warm shades (red, orange, and crimson) are more often used than cold shades (azure, dark blue, light green, and dark green). Colours are mainly used to create shape outlines, but not for colouring. The lines are often intermittent, uneven. In general, in this group of patients, manifestations of perseveration and rotation are more common than in other clinical groups. The drawings of patients with organic mental disorders were described by a more or less significant decrease in scores on most scales, including scales such as Scale No. 13, Rotation and Scale No. 14, Perseveration, the decline of which is usually not inherent in other clinical groups. However, the difference from the healthy group on scale No. 13, Rotation was noted as a tendency but did not reach a statistically significant level.

Comparison of the drawings of patients of this group with other clinical groups showed statistically significant differences on the scale No. 1, Colour Meaning (from Group 3), Scales No. 2, Colour Adequacy (from group 3), Scales No. 8, Problem Solving (from Group 1), No. 11, Line Quality (from Groups 1 and 3), No. 14, Perseveration (from groups 1 and 3 ). It is noteworthy 
that the drawings of this group were distinguished by a higher quality of the line (Scale No. 11) from the group of patients with schizophrenia, but lower in comparison with the group of patients with oligophrenia and healthy.

The most specific features of this clinical group: low degree of integration of image elements; tree, apple, and human are depicted separately from each other. There are several apples disproportionately large in size and of different colours. A human makes no effort to take an apple. The blue colour of apples and trees does not match the subject of the image. There are manifestations of perseveration in the form of dots on a person's face, branches of the same type. There is no sense of perspective and volume. The image of a human figure is rather schematic than realistic. There are no important body parts, such as fingers and ears. The image at large resembles an image of a 4-5-yearold child.

The definition of schizophrenia as a single symptom complex, as is known, is impossible. At the same time, in the international classifications of mental illnesses, there remains a tendency to highlight the symptoms necessary for schizophrenia, which substantially reflect the symptoms of the first rank (auditory pseudohallucinations, auditory hallucinations in the form of dialogues and commentary content, somatic sensations of external influences, the openness of thoughts, feelings of withdrawal of thoughts and their transmission from a distance, ideas of impact) and fundamental symptoms - associative disorders, affective flattening, and violation of the sense of "l", autism and ambivalence. Types of dynamic characteristics or combinations of symptoms that are more or less stable for individual stages of the disease can be considered as conditionally pathognomonic for this disease, as against individual signs.

E.E. Svistovskaya and A.I. Kopytin conducted a pilot study using ATSFE in patients with schizophrenia, organic mental illnesses and determined that patients with schizophrenia are described by tight control of the visual process, restrictions on the choice of themes, the use of artistic materials and a set of colours; amorphous, ornamental, fantastic images; difficulty in interpreting; dependence on therapist; limitation of communication methods (in verbal and projectivesymbolic ways) [17-19]. In the process of art therapy, these features undergo positive changes, which is reflected both in the visual production and in intragroup relations. Considering the combination of formal signs of patterns inherent in this disease, the severity of acute psychotic symptoms associated with the manifestations of symptoms of the first and second rank should be taken into consideration. However, the formal features of the pattern can be determined not only by the severity of the manifestation of these symptoms but also by a violation of associations, affects, as well as autism and ambivalence.

Patients with an acute psychotic state create illogical, chaotic patterns with unusual details. They also tend to use a large number of colours that are not compatible with each other and inadequate to the subject of the image. Patients with chronic schizophrenia, without acute psychotic symptoms, create drawings with a small amount of detail, an unrealistic image of people, and a limited number of colours. The solution to the problem is also on a low level. Further research may be aimed at clarifying whether negative symptoms of schizophrenia (such as autism and emotional-volitional decline) are associated with low rates on problem-solving scales, colour values, details of objects and the environment, and positive symptoms (hallucinations, delirium) -with low scores on logic and integration scales.

Drawings of patients with schizophrenia are described by a more or less significant decrease in scores, primarily on scales such as Scale No. 1, Colour Meaning, Scale No. 2, Colour Adequacy, Scale No. 3, Energy, Scale No. 4, Space, Scale No. 5, Integration, Scale No. 6, Logic, Scale No. 7, Realism, Scale No. 8, Problem Solving, Scale No. 10, Details, Scale No. 12, Human. However, it is obvious that within this group, several subgroups can be distinguished, described by a different combination of formal features. Comparison of the drawings of this group with other clinical groups showed statistically significant differences on the scale No. 1, Colour Meaning (from group 3), No. 2, Adequacy of colour (from group 3), No. 3, Energy (from group 3), No. 4, Space (from group 3), No. 5, Integration (from group 2), No. 8, Problem Solving (from groups 2 and 3 ), No. 10, Details (from group 2), No. 11, Line Quality (from groups 2 and 3), No. 14, Perseveration (from group 2).

A manic state can be associated with various affective disorders, such as bipolar affective disorder, cyclothymia. Manic manifestations can also occur as part of a more complex clinical picture associated with schizophrenia and delusional disorders. A wide range of different manifestations associated with this disorder should be taken into consideration, which may be, in 
particular, conditioned by the severity of manic symptoms. In some cases, with slightly pronounced manic symptoms (hypomanic state), the patterns will be practically indistinguishable from the patterns of healthy people, especially considering the presence of many subtypes of patterns of healthy individuals associated with their characterological features. Such patterns can be distinguished by increased colour, the use of the entire space, an abundance of details. In general, their high expressiveness and creativity can also be noted.

In a hypomanic state, patient drawings are described by a fairly high integration, somewhat higher than normal, an indicator of energy and detail, as well as a variety of lines. Increased creativity may occur. Sometimes drawings of healthy people are mistakenly assigned to this category of drawings. The more pronounced symptoms of a manic state are, the more such an indicator as a solution to a problem will be violated. The drawings will become less realistic and contain an excessive amount of detail. At the height of the manic state, the drawings may differ in everyday life in colour terms, with a small number of details, with swift lines. The drawing will also be less meaningful due to the patient's inability to concentrate on the activity. They will quickly complete the creation of the drawing and proceed to the creation of new.

There are subtypes such as mania without psychotic symptoms (F30.1) and mania with psychotic symptoms (F30.2, according to ICD-10). In the latter case, apart from high spirits, expansiveness, and irritability, as well as disorganisation of daily activities, hallucinatory-delusional manifestations are noted (but not corresponding to those inherent in schizophrenia). Moreover, the patterns of manic patients with psychotic symptoms will differ little from the patterns of patients with schizophrenia. Logic scores may decline; paradoxical elements may appear in the picture.

According to C. Tisdale, the task of art-therapeutic work is to encourage the group members to learn through the experience that they had not previously realised, to "open up" the logic and arguments of certain previously unrecognised acts [20, 21]. The more understandable the patient becomes for themself, the better they comprehend the effects of the influence of their own personality on others, the more they will be capable of comprehending possible deviations in their behaviour. Fine art is a safe way of expressing aggression. Therefore, it can be used to objectify emotional processes and understand them, as well as increase self-acceptance and self-esteem of patients based on the recognition of their experiences in the process of their interaction with each other, art therapist, and other medical personnel.

\section{CONCLUSIONS}

The workshop is a creative demonstration by the teacher of the stages of the work and the parallel performance by students with the teacher of the same task. Also, a workshop, as a quick and illustrative example in the performance of a watercolour etude by a teacher, is the strongest means of aesthetic impact, which is to show the secrets of drawing mastery, aesthetic techniques of working with watercolour, brush movements, the appearance of colour fillings, emphasizing pictorial composition.

Almost every mentally ill person (regardless of age) can participate in art-therapeutic work, which does not require them to have any visual arts or artistic skills. Art therapy is a means of predominantly non-verbal communication. This makes it especially valuable for those patients who do not have a good command of speech, find it difficult to describe their experiences verbally. Since visual activity is a powerful means of bringing people together, art therapy awakens, shapes, and supports patients' communicative abilities and collectivist tendencies. This is especially valuable in situations of mutual exclusion, with difficulties in establishing contacts, manifestations of autism. Being a means of free expression, art therapy involves an atmosphere of trust, tolerance, and attention to the inner world of the patient and group members to each other.

Fine art products are objective evidence of the patient's mood and thoughts, which allows them to use them to assess the condition and conduct diagnostic studies. In most cases, art therapeutic work evokes positive emotions in patients, helps them overcome apathy and lack of initiative, even with pronounced personality changes, forms a more active life position, emotionally valuable acceptance of partners, and their cohesion into a group.

In our opinion, the Art-therapeutic scales of formal elements can be used to solve various psychodiagnostic tasks related to the simultaneous or dynamic assessment of mental processes and aspects of mental functioning: assessment of mental state, cognitive, emotional processes; clinical nosological and syndromological diagnosis; diagnosis of development, 
including particular violations of the development process (general or partial); differential diagnosis (in difficult cases in diagnostic respect); assessment of the intermediate and final effects of treatment and rehabilitation (including art therapy), manifested at the level of symptoms and different mental processes.

The data obtained using ATSFE can be factored in when planning art therapy and other types of treatment, identifying the strengths and weaknesses of the patient and their adaptive capabilities, and determining individual rehabilitation route. In general, the use of ATSFE corresponds mainly to the clinical level when conducting an integrative multilevel art-therapeutic psychodiagnosis.

\section{ACKNOWLEDGEMENT}

None.

\section{REFERENCES}

[1] Alexandrian S. Panorama du cubisme. Paris: Filipacchi 2011.

[2] Florensky PA. Analysis of spatiality in artistic works. Decorative art. Moscow: Mysl' 2000.

[3] Kulikova IS. Expressionism in art. Moscow: BMM 2007.

[4] Bouleau Ch. The painter, secret geometry. A study of composition in art. New York: Dover Publications 2001.

[5] Johnson F, Gorton J. Art the illustrations of Rockwell Kent: 231 examples from books, magazines, and advertising art
(Dover fine art, history of art). New York, Dover Publications 2008.

[6] Burne JD. The prints of Rockwell Kent: A catalog Raisonne. Chicago, University of Chicago Press 2006.

[7] Favorsky VA. About the artist, about creativity. Moscow: Soviet artist 2000.

[8] Favorsky VA. About composition. Moscow: Iskusstvo 2012.

[9] Andreev LG. Surrealism. Moscow: Vusshaia shkola 2012.

[10] Sarabyanov DV. Art Nouveau style. Moscow: Iskusstvo 2012.

[11] Sarabyanov D. Robert Falk. Dresden: Verlag der Kunst 2000.

[12] Gregory R. Reasonable eye. Moscow: Mir 2000.

[13] Lissitzky E. Erinnerungen, briefe, schriften, ubergeben von Sophie Lissitzky Kuppers. Dresden: Verlag der Kunst 1999.

[14] Feist PH. French impressionism. Germany: Benedikt Taschen Verlag GmbH 2005.

[15] Hamann R, Hermand J. Expressionismus. Berlin: Akademie 2010.

[16] Saarikivi S, Niilonen K, Ekelund H. Art in Finland. Helsinki: Schildts 2000.

[17] Hitchcock HR. Architecture, 19th, and 20th centuries. Harmondsworth: Penguin Books 1999.

[18] Jenny P. Drawing techniques. New York: Princeton Architectural Press 2012a.

[19] Jenny P. Figure drawing. New York: Princeton Architectural Press 2012b.

[20] Jenny P. The artist's eye. New York: Princeton Architectural Press 2012c.

[21] Passeron R. Phaidon encyclopedia of surrealism. Oxford: Phaidon 2010.

Received on $25-07-2020$

Accepted on 18-08-2020

Published on 14-09-2020

DOI: https://doi.org/10.6000/2292-2598.2020.08.03.23

(C) 2020 Orazalieva et al.; Licensee Lifescience Global.

This is an open access article licensed under the terms of the Creative Commons Attribution Non-Commercial License (http://creativecommons.org/licenses/by-nc/3.0/) which permits unrestricted, non-commercial use, distribution and reproduction in any medium, provided the work is properly cited. 